\title{
A participatory evaluation of the life-skills training programme in Myanmar
}

UNICEF

Population Council

Follow this and additional works at: https://knowledgecommons.popcouncil.org/departments_sbsr-pgy

Part of the Community Health and Preventive Medicine Commons, International Public Health Commons, and the Women's Health Commons

How does access to this work benefit you? Let us know!

\section{Recommended Citation}

UNICEF and Population Council. 2000. "A participatory evaluation of the life-skills training programme in Myanmar." Bangkok: Population Council. 


\title{
A Participatory Evaluation of the Life-skills Training Programme in Myanmar
}

\author{
UNICEF/Myanmar \\ and \\ Population Council/Thailand
}

(f Population Council 
The Population Council is an international, nonprofit, nongovernmental institution that seeks to improve the wellbeing and reproductive health of current and future generations around the world and to help achieve a humane, equitable, and sustainable balance between people and resources. The Council conducts biomedical, social science, and public health research and helps build research capacities in developing countries. Established in 1952, the Council is governed by an international board of trustees. Its New York headquarters supports a global network of regional and country offices.

Copyright $@ 2000$ by The Population Council, Inc. 


\section{TABLE OF CONTENTS}

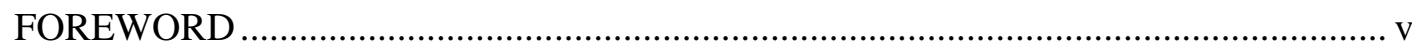

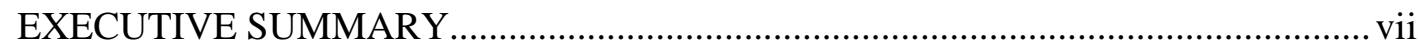

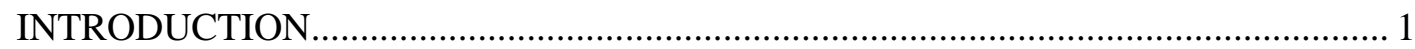

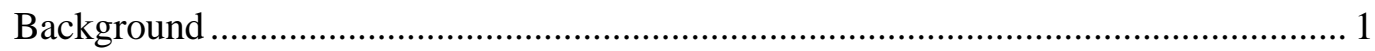

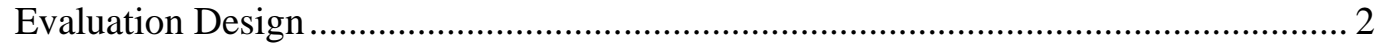

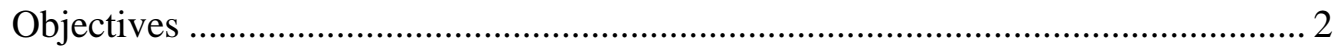

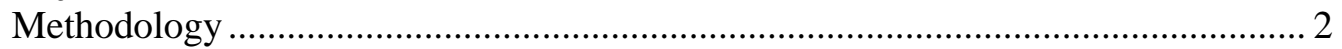

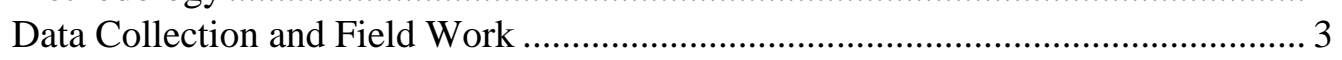

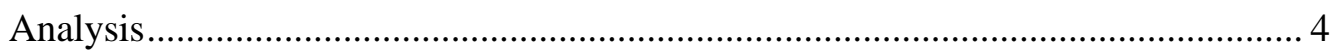

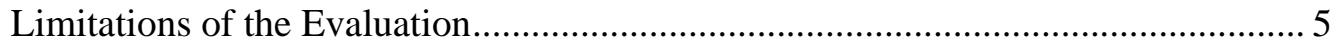

LIFE-SKILLS TRAINING FOR WOMEN ............................................................ 7

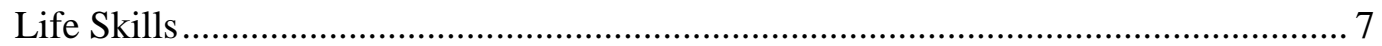

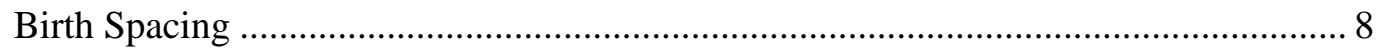

Knowledge of Sexually Transmitted Diseases........................................................... 8

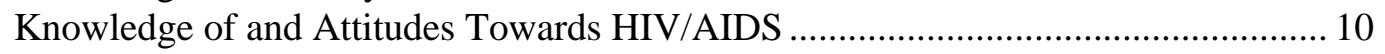

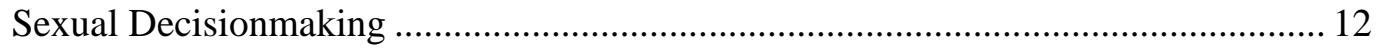

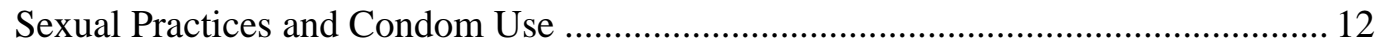

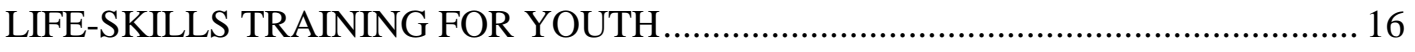

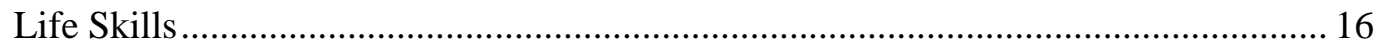

Knowledge of Sexually Transmitted Diseases......................................................... 17

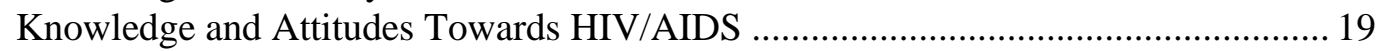

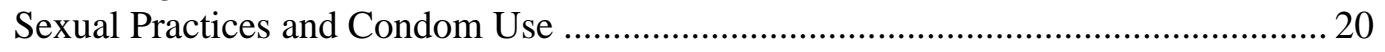

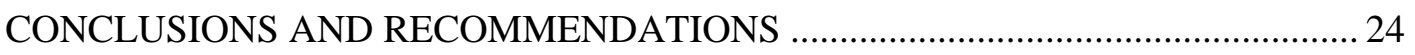

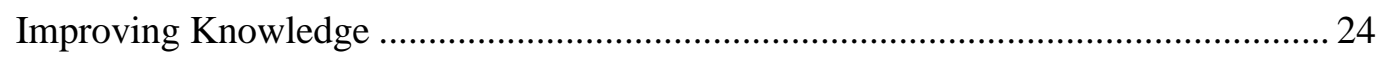

Improving the Impact of Life-skills Training on Behaviour...................................... 25

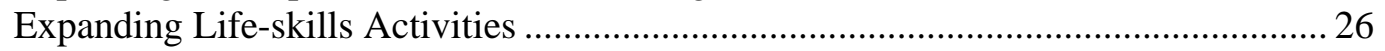

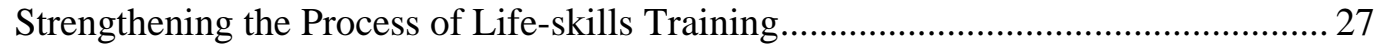

Ensuring the Appropriate Choice of Participants ........................................................ 28 


\section{FOREWORD}

In the context of the Prevention of HIV/AIDS activities, and in preparation of the June 1998 mid-term review of UNICEF/Myanmar's Country Programme of Cooperation, 1996-2000, a participatory evaluation of the life-skills training programme in Myanmar was conducted from August 1997 to March 1998.

Through a participatory evaluation of the life-skills training programme, the three collaborating partners-UNICEF/Myanmar, the Myanmar Maternal and Child Welfare Association, and the Myanmar Red Cross Society-have been able to identify areas in which project activities could be strengthened, and to revise activities to respond to issues raised in the evaluation. A review of the training manual is underway, and revisions will reflect the findings and recommendations resulting from this evaluation. In addition to revising the training manual, UNICEF/Myanmar is reviewing and revising the process and methodology of training, with the objective of addressing a number of areas identified during the evaluation that require strengthening. One of the key findings of this evaluation was the limitations inherent in including only women in the training activities. UNICEF/Myanmar is currently exploring a number of methods by which husbands and men could play a more substantial role in the training.

The participatory evaluation and the resulting improvements to the life-skills training programme activities would not have been possible without the dedication of many individuals and organisations both within Myanmar and internationally. Gratitude must go to Michelle Gardner of the Population Council/Thailand and Myo Zin Nyunt and Thazin Oo from UNICEF/Myanmar for the time and effort they have spent on conducting the final analysis of the evaluation and preparing this report. Many thanks must also go to all the trainers from the Myanmar Red Cross Society and the Myanmar Maternal and Child Welfare Association for their dedication to the life-skills training programme. We are grateful for their invaluable support throughout the data collection and analysis that have led to this report.

Appreciation is due to Yukolsiri Surasrang and Kanokwan Tharawan of the Population Council/Thailand who worked closely with UNICEF/Myanmar to get the evaluation activities underway. Special acknowledgement also goes to Megan Douthwaite and Simonetta Cengarle from the Population Council/Thailand and Amaya Maw Naing for their assistance with putting the finishing touches to this document. The participatory evaluation and this report were made possible with the financial support of The Rockefeller Foundation, with Jane Hughes providing valuable advice throughout the evaluation process. And finally, both UNICEF/Myanmar and the Population Council/Thailand are grateful to all those women and young people who were willing to participate in the evaluation activities, without whom this activity could not have happened.

\author{
Dr. Juan Aguilar Leon \\ Representative \\ UNICEF/Myanmar
}

\author{
Dr. Christopher Elias \\ Country Director \\ Population Council/Thailand
}


vi A Participatory Evaluation of the Life-skills Training Programme in Myanmar 


\section{EXECUTIVE SUMMARY}

In 1993 UNICEF/Myanmar launched an innovative project aimed at preventing the further spread of HIV/AIDS in Myanmar through the promotion of reproductive health. One of the activities undertaken was life-skills training for women and youth, conducted in collaboration with the Myanmar Red Cross Society (MRCS) and the Myanmar Maternal and Child Welfare Association (MMCWA). The objective of the life-skills training activities was to encourage and promote informed decisionmaking and careseeking behaviour among youth and women. The training aims to provide detailed and accurate information concerning sexuality, birth spacing, sexually transmitted diseases (STDs), and HIV/AIDS, and to provide skills for youth and women to enable them to cope with their daily lives and become proponents of community mobilisation.

This report presents findings of a participatory evaluation of the life-skills training activities implemented in late 1997 and early 1998. At the time of the evaluation, lifeskills training had been conducted in 27 project townships. MRCS activities targeted youth aged 15-25 years, and MMCWA worked primarily with married women aged 2040 years. Eight project townships were identified as project evaluation areas and one township was selected as a comparison township for each of the implementing organisations. In each of the selected project townships in-depth interviews and focusgroup discussions were conducted with trained and non-trained individuals in urban and rural areas. The evaluation used a highly participatory approach in order to encourage self-reflection among the local implementing agencies. The following summarises the findings and recommendations resulting from the participatory evaluation.

- Positive impact of life-skills training: In general, knowledge of HIV and AIDS was greater than that of STDs, indicating the positive impact of the training program in delivering needed knowledge. Accurate information regarding STDs is hard to come by in Myanmar and, hence, more accurate knowledge of these diseases among trained youth and women is likely to be due to their life-skills training.

- Improved knowledge and attitudes towards people living with HIV/AIDS: Young people and women who took part in the life-skills training programme benefitted from the training in terms of their personal knowledge and in terms of influencing their attitudes towards people living with HIV/AIDS. Consequently, expanding access to this intervention in other townships of Myanmar should be pursued.

- Limited impact of friend-to-friend counselling: Non-trained youth and women in project townships were generally found to have only slightly greater knowledge than their counterparts in the comparison townships. It would seem that the anticipated multiplier effect of friend-to-friend counselling has been limited. One way to strengthen the programme would be to pay more attention to the friend-to-friend component of the training, and to focus on reaching those individuals who are most likely to pass information on to other people in the community.

- Gaps in knowledge: While most trained women and youth were better informed about reproductive health issues than their non-trained counterparts, the evaluation identified specific areas where understanding and knowledge was either incomplete or inaccurate. For example, issues related to partner notification and adherence to 
prescribed courses of antibiotic treatment among individuals with STDs were not sufficiently understood to promote appropriate behaviour. There is a need to consider revising the training manual to address identified misperceptions and gaps in knowledge.

- Need for refresher training: In a number of cases trained women and youth were found to have good general knowledge but incomplete information on specific details. This would imply either that all the information from the training was not absorbed or that it was forgotten over time. The sustainability of the impact of life-skills training activities could be addressed through the implementation of regular refresher training.

- Continued stigmatisation of condoms: Trained participants continued to report low condom use despite increased knowledge, primarily because of the method's association with promiscuity and commercial sex. Encouraging participants to open, touch, and unroll condoms in the training sessions may help to demystify the method.

- Low perception of personal risk: The perception of personal risk of acquiring STDs or HIV among the women who had participated in the training was still limited. If behaviour change is to occur, women need to be able to accurately assess their personal risk. The life-skills training could be strengthened by the use of a number of techniques, such as case histories or role-playing, to help women identify their personal risk of STDs or HIV.

- Sexual decisionmaking still in the hands of the husband: The evaluation found that husbands were the predominant decisionmakers in relation to sexual matters. To transfer knowledge into behaviour, women need to enhance their ability to negotiate and discuss sexual issues with their husbands. Addressing gender and gender relations in the training and including men in training activities would significantly enhance the possibility that changes in behaviour will result.

- Importance of evaluation and sharing of experience: Through participatory evaluation, MMCWA and MRCS were provided with a forum for identifying and addressing problems. The evaluation highlighted the similarities of many of the problems and limitations experienced by the two implementing organisations. There is value in the development of an integrated evaluation and monitoring system, and a forum for routine sharing of experiences between MMCWA and MRCS trainers.

- Importance of selecting appropriate participants: Most of the women involved in the MMCWA training and evaluation activities were from the older end of the 20-40 year age range. It is clear, however, that younger women also need to be included in the training, as they are often unaware of reproductive health issues. Future activities will be most effective if a broad range of individuals are involved in the training.

Through the participatory evaluation of the life-skills training programme, UNICEF/Myanmar, MMCWA, and MRCS have been able to identify areas in which project activities could be strengthened and to revise activities in response to issues raised in the evaluation. Many of the recommendations resulting from the evaluation and presented in this report are already being incorporated into project activities. 


\section{INTRODUCTION}

\section{Background}

In 1993 UNICEF/Myanmar launched an innovative project aimed at preventing the further spread of HIV/AIDS in Myanmar through promotion of reproductive health. In partnership with the Ministry of Health, the Myanmar Maternal and Child Welfare Association (MMCWA), the Myanmar Red Cross Society (MRCS), and the Myanmar Medical Association, a number of activities were undertaken to achieve the general objective of preventing transmission of sexually transmitted diseases (STDs) and HIV/AIDS among young people and women of reproductive age. The focus of this partnership has been on the expansion and upgrading of reproductive health services and the provision of community-based education in reproductive health, including HIV/AIDS, STDs, and life skills.

This report presents the findings of a participatory evaluation of the life-skills training ${ }^{1}$ activities conducted in collaboration with MRCS and MMCWA. At the time of the evaluation, life-skills training efforts were being implemented in 27 project townships (Table 1). MRCS activities targeted young people aged 15-25 years, while MMCWA worked primarily with married women aged 20-40 years. The objective of the life-skills training activities was to encourage and promote informed decisionmaking and careseeking behaviour among youth and women. The training aimed at providing detailed and accurate information concerning sexuality, birth spacing, STDs, and HIV/AIDS. It also provided skills to help young people and women cope with their daily lives in order to become proponents of community mobilisation. The programme was designed as a training-of-trainers programme, and participants in the life-skills training course were encouraged to further disseminate skills to their peers through friend-to-friend or community counselling activities.

\section{Table 1: Life-skills training project townships}

\begin{tabular}{ll}
\hline State or Division & Project Townships \\
\hline Ayeyarwaddy Division & Hinthada, Pathein (West), Ma U Bin \\
Bago Division & Bago, Pyay \\
Chin State & Haka \\
Kachin State & Myitkyina, Bamaw \\
Kayah State & Loikaw \\
Kayin State & Paan \\
Magway Division & Magway, Pakokku \\
Mandalay Division & Meikhtila, Myingyan, Chanaye Thazan, Mahaaungmyay \\
Mon State & Mawlamyine \\
Rakhine State & Sittwe \\
Sagaing Division & Shwebo, Monywa \\
Shan State & Lashio, Tachileik, Taunggyi \\
Tanintharyi Division & Dawei, Kawthaung \\
Yangon Division & Insein, South Okkalapa \\
\hline
\end{tabular}

${ }^{1}$ Life-skills training included eight lessons: Happy and Healthy Living; Community-based Counselling; Friend-to-Friend Education; How to Make Good Decisions; Reproductive Health, Birth Spacing, and STDs; HIV/AIDS; Tuberculosis; and Family and Community Care for Persons Living with HIV/AIDS. 
From May to October 1994, training manuals ${ }^{2}$ were prepared with the technical assistance of the Thai Red Cross Society, and the first training of core trainers took place in December. These core trainers then trained township-level facilitators in the 27 project townships. Between 1994 and 1995, 10 MRCS and 12 MMCWA core trainers trained 594 township facilitators (297 young people and 297 women). The trained township facilitators returned to their townships and conducted eight two-day training sessions in both urban and rural areas, for a total of 16 training sessions. A total of 17,280 young people and 17,280 married women participated in the training between 1994 and 1996.

In 1996 a decision was taken to conduct a participatory evaluation of the life-skills training activities. The primary purpose of the evaluation was to encourage self-reflection among the local implementing agencies (i.e., MRCS and MMCWA) in order to improve the implementation of the life-skills intervention at the community level. This was seen as a useful exercise, given plans to expand the life-skills training activities to additional townships. As no prospective evaluation had been included in the original project design, given the lack of any baseline data, no attempt was made to conduct a formal evaluation of the broader impact of the life-skills training programme.

\section{Evaluation Design}

\section{Objectives}

In order to determine the effectiveness of the current training activities in improving the skills of direct project participants as well as their subsequent activities as friend-to-friend counsellors within their communities, three key objectives were identified for the participatory evaluation of the life-skills training programme:

1. To assess the effect of life-skills training among the target populations of married women and youth;

2. To assess the multiplier effect of the training among the non-trained population in the project areas; and

3. To assess the capacity-building processes of local counterparts and their understanding of the ongoing programmes (both training and evaluation).

The focus was on identifying which components of the life-skills curriculum and training need to be modified to make the training more relevant and interesting for young people and married women.

\section{Methodology}

The evaluation was conducted in a highly participatory manner. Hence, MMCWA lifeskills trainers conducted the evaluation of the life-skills programme for women of reproductive age, and MRCS trainers conducted the evaluation of the youth component. The Population Council/Thailand provided training in participatory evaluation methods. The participatory approach taken in this evaluation was an extension of the methods used

\footnotetext{
${ }^{2}$ UNICEF (1994) Reproductive Health and HIV/AIDS Training Manual. Yangon: UNICEF; Myanmar Red Cross Society (1994) Happy Healthy World for Youth: Life Skills training. Yangon: UNICEF; and Myanmar Maternal and Child Welfare Association (1994) Life Skills Training for Married Women (Housewives). Yangon: UNICEF.
} 
during curriculum development and the intervention activities themselves. It produced an increased sense of ownership by the implementing agencies over the evaluation process and the findings of the evaluation. The evaluation plan was initiated in mid-1996 by MMCWA, MRCS, and UNICEF/Myanmar, with technical assistance from the Population Council/Thailand.

A weeklong planning workshop in Yangon was conducted for central-level core trainers in August 1996. The workshop involved participants from both MMCWA and MRCS and focused on participatory evaluation methods, including consideration of different data collection methods and analysis plans. Unfortunately, due to travel restrictions in place at that time, it was not possible for representatives from the project townships to attend the workshop. Participants defined key areas for assessment during this workshop and drafted guidelines for focus-group discussions and in-depth interviews.

In October 1996 MRCS and MMCWA each sent five trainers from each selected township to attend a second training programme in participatory evaluation methods. These weeklong workshops, also held in Yangon, were convened separately for MRCS and MMCWA. The data collection instruments developed during the workshop of centrallevel trainers were pre-tested during this second training activity and were revised accordingly. ${ }^{3}$ As a result of administrative delays, data collection could not begin immediately after the training workshops. Consequently, refresher training for townshiplevel trainers from MMCWA and MRCS in the process of data collection and analysis took place in June and July 1997, respectively.

\section{Data Collection and Field Work}

Eight project townships were identified as evaluation project areas (Table 2), and one township without training was selected as a comparison township for each of the two implementing organisations (Patheingyi in Mandalay Division for MRCS and Hmawbi in Yangon Division for MMCWA). Data were collected between August 1997 and March 1998. Township-level trainers collected data in their own townships, while central-level trainers from MMCWA conducted interviews in Hmawbi, and MRCS trainers from Mandalay collected data in Patheingyi.

Table 2: Townships included in the participatory evaluation

\begin{tabular}{ll}
\hline State or Division & Project Township \\
\hline Ayeyarwaddy Division & Hinthada \\
Bago Division & Bago \\
Kachin State & Myitkyina \\
Kayin State & Paan \\
Magway Division & Pakokku \\
Mandalay Division & Mahaaungmyay \\
Shan State & Lashio \\
Tanintharyi Division & Dawei \\
\hline
\end{tabular}

\footnotetext{
${ }^{3}$ Readers interested in receiving a copy of the evaluation guidelines can contact: The Population Council, P.O. Box 138 Pratunam, Bangkok 10409, Thailand, Tel + 662653 8586-7/251 4766/ 251 7066, Fax +66 2 255-5513 e-mail: pcbkk@ popcouncil.th.com; or UNICEF P.O. Box 1435 Yangon, Myanmar. Tel: +95 1 212 086/087/090/091, Fax: +95 1212 063/089.
} 
Data collection was qualitative and involved the use of in-depth interviews and focusgroup discussions. In each of the project townships, interviews and focus-group discussions were conducted with both trained and non-trained individuals. The nontrained participants were defined as individuals from the project townships who were family members or friends of the trained participants and who may have received information from trained youth and married women. Interviews and focus-group discussions took place in both urban and rural areas, and were tape-recorded and transcribed for analysis.

MRCS conducted three focus-group discussions in each project township: one with trained urban youth, one with non-trained urban youth, and one with trained rural youth. In-depth interviews were also conducted in project townships with two trained urban youth, one non-trained urban youth, two trained rural youth, and one non-trained rural youth. In the comparison township, one focus-group discussion was conducted in the urban area and one in the rural area. In addition, two in-depth interviews were conducted with urban youth and four with rural youth (Table 3). Of the young people interviewed during the evaluation activity, approximately two-thirds were male. Their mean age was 19 years, and two-thirds had attended high school or university.

MMCWA also conducted three focus-group discussions and six in-depth interviews in each project township. In the comparison township they conducted one focus-group discussion and two in-depth interviews in both the rural and urban areas (Table 3). Participants in the evaluation of the life-skills training for women of reproductive age were, on average, 33 years old. Just under one-third of the women were illiterate or had attended only primary school, and nearly half had attended high school or university.

Table 3: Interviews and focus-group discussions conducted during the participatory evaluation

\begin{tabular}{lrrrrrrrr}
\hline & \multicolumn{3}{c}{ MRCS (youth) } & & \multicolumn{3}{c}{ MMCWA (women) } \\
\cline { 2 - 4 } \cline { 7 - 8 } & IDI & FGD & Total & & IDI & FGD & Total \\
\hline Trained urban & 16 & $8(64)$ & 80 & & 16 & $8(80)$ & 96 \\
Non-trained urban & 8 & $8(64)$ & 72 & & 8 & $8(80)$ & 88 \\
Trained rural & 16 & $8(64)$ & 80 & & 16 & $8(80)$ & 96 \\
Non-trained rural & 8 & & 8 & & 8 & & 8 \\
Control urban & 2 & $1(8)$ & 10 & & 2 & $1(10)$ & 12 \\
Control rural & 4 & $1(8)$ & 12 & & 2 & $1(10)$ & 12 \\
\hline Total & $\mathbf{5 4}$ & $\mathbf{2 6}(\mathbf{2 0 8})$ & $\mathbf{2 6 2}$ & & $\mathbf{5 2}$ & $\mathbf{2 6}(\mathbf{2 6 0})$ & $\mathbf{3 1 2}$ \\
\hline
\end{tabular}

Note: Number of participants in each focus-group discussion in parentheses.

IDI = in-depth interview; FGD = focus-group discussion.

\section{Analysis}

A team of personnel from MMCWA, MRCS, and UNICEF/Myanmar conducted a content analysis of the transcripts of the focus-group discussions and the in-depth interviews in the Myanmar language. The analysis focused on the role and limitations of the life-skills training programmes implemented by MMCWA and MRCS. The following subject areas were the major themes of the analysis: life-skills, knowledge of birth spacing, knowledge of STDs, knowledge and attitudes towards HIV/AIDS, sexual practices, and condom use. 
Data were coded by hand and sorted by their significance and relevance. A comparison of the sorted data was performed between different groups, including male and female; students and workers; and trained urban, non-trained urban, trained rural, non-trained rural, and comparison groups. The analysis was reviewed by staff members from the Population Council/Thailand, who assisted in the interpretation and preparation of this report.

Because the life-skills training activities of MMCWA and MRCS are essentially independent programmes, albeit with similar philosophies, the findings from the evaluations of the two programmes were analysed separately, and the findings are presented separately below.

\section{Limitations of the Evaluation}

When considering the findings and recommendations of the participatory evaluation of the life-skills training programme, it is important to bear in mind a number of limitations inherent in the evaluation design. First, it is not valid to generalise broadly from the results of the evaluation. Because it is a qualitative evaluation, the respondents are a select group and may not be representative of all the communities and individuals participating in the life-skills training activities. Nevertheless, the evaluation does provide useful and valuable insights into the impact and acceptability of the interventions. Second, the evaluation is not independent. It was specifically designed to be participatory in that the life-skills trainers themselves were evaluating the training activities they had implemented. This leads to some bias from both the interviewer and the respondent, but also ensures commitment to the implementation of the recommendations. 


\section{LIFE-SKILLS TRAINING FOR WOMEN}

All trained participants were able to discuss the training they had received and the specific components. They also discussed the positive changes in their lives and their communities that they attributed to the training. Most of the non-trained people had heard about the training from family members or friends in their communities. Generally, however, the urban non-trained women knew more about the training than their rural counterparts.

"After this training we learned a lot about health issues. Moreover, we are able to make good decisions and choices which lead to a happy and healthy family life." (A trained urban woman from Bago)

"I did not attend that training. But I heard about it from my neighbours. It was informative and interesting. Not only in health issues but also in social and developmental aspects." (A non-trained urban woman from Pakokku)

\section{Life Skills}

The component of the life-skills training that focused on general life skills included discussions of the important characteristics of a good husband, good decisionmaking, and friend-to-friend education and support.

Women mentioned a broad range of characteristics they look for in yauk kyar kaung (a good husband). Almost all women, regardless of their training or residence, mentioned $t a$ lin ta maya (monogray, literally "one husband, one wife") and thitsar shi (faithfulness). These characteristics, emphasised as top priorities by the trained women, were not as important to many of the non-trained women as sar wut nay yay phulon (economic security, literally "enough to eat, wear, and live") and chit khin kyin nar (tender loving care). Fewer women in the comparison township mentioned monogamy and faithfulness than either trained or non-trained women in the project townships. Other characteristics mentioned by many women were barthar yay kine shine (religiousness), tha baw tha kyee (broadmindedness), and kwint lut (forgiveness).

"A good husband must be faithful. He must practice monogamy and earn for the family to make ends meet." (A trained urban woman from Dawei)

"A good husband brings home all his salary and helps me with household chores. Of course, he needs to be faithful too." (A non-trained urban woman from Lashio)

During discussions of good decisionmaking, it was clear that the trained participants recognised the importance of making informed life decisions in order to address needs and solve problems and had acquired many of the skills that would enable them to do so. Non-trained women in urban areas were less comfortable discussing this subject, and those in the rural project areas and the comparison township generally seemed to lack the knowledge and skills to ensure optimal decisionmaking regarding reproductive health and the prevention of STDs. The importance of maintaining good friendships in the community and good relationships within the family was also mentioned by trained women, but rarely by those who had not received training. 
"We became thoughtful after this training. Each and every thing we do, we consider its consequences, the positive and negative effects of our actions." (A trained urban woman from Pakokku)

\section{Birth Spacing}

The birth-spacing component of the life-skills training curriculum aimed to increase women's awareness of the advantages of spacing births, the availability of methods and services, and the characteristics of different methods.

Discussions of desired family size revealed that the greatest number of children were desired by women from the comparison township, who generally wanted between three and five children. Trained women from both urban and rural areas expressed the desire to have just two or three children, while non-trained women in urban areas wanted between two and four, and those in rural areas between two and five children.

"The number of children ... minimum one and maximum three. It is because of economics, health care, education, and social reasons. And three is the most we can afford." (A trained urban woman from Hinthada)

"How many children? Well, I want as many as possible. Children are jewels of the family. If I have many children, they can look after me. We can have a strong group of relatives." (An urban woman from Hmawbi, the comparison township)

Both trained and non-trained women in the project townships, and those in the comparison township, demonstrated substantial knowledge of birth spacing. Most participants knew a broad range of methods and service providers, with knowledge generally higher among trained women and those in urban areas. Information regarding birth spacing was clearly available from a number of sources other than the life-skills training project. Many non-trained participants reported receiving messages on birth spacing from health talks, maternal and child health clinics, antenatal care centres, books and pamphlets, and by word of mouth through elders and friends in the community.

Some women commented that, because of the birth-spacing component of the training, they were more aware of the different methods of birth spacing, which is likely to have an impact on the number of unwanted pregnancies and abortions in the community. Detailed knowledge of specific methods was, however, found to be less complete, particularly among non-trained women and those in the comparison township.

"For birth spacing I'd prefer to take injection, pills, or undergo sterilisation. I know about condoms but I don't like it and don't want to use it either. Maybe it can cause diseases such as thar ain [uterine, literally "home for baby"] cancer" (A non-trained urban woman from Myitkyina)

\section{Knowledge of Sexually Transmitted Diseases}

A major focus of MMCWA's life-skills training curriculum was on issues related to STDs. Topics included transmission, seriousness, treatment, symptoms, and the relationship of STDs to HIV transmission. 
Almost all participants in the evaluation had heard of STDs, although the language used to describe them varied with regional dialects. For example, in Paan the term lu pyo nar yawgar (young boys' disease) is common, while the slang word pha kyo (broken by a prostitute) is common in many other townships. Women from the comparison township were less likely than those from the project townships to have heard of STDs.

The majority of all respondents could identify some of the symptoms of STDs. A number of those who had not been trained, however, defined itching skin disorders and white patches on the skin as STDs. Some respondents confused STDs with skin diseases such as ko yay pyar yawgar (leprosy, literally "body skin disease") and believed that leprosy lesions were a sign of advanced syphilis. Most of the trained participants were able to mention sipalit (syphilis), yay yone (herpes, literally "water rabbit"), and a phyu sin (white discharge) as STDs, and a few also mentioned genital warts.

"We hear about karlathar yawgar [venereal disease, literally "adolescent males' disease"] quite often but do not know very much about it. It seems to me a leprosy-like disease and can be transmitted easily to someone with the same blood group." (A non-trained rural woman from Hinthada)

Transmission and prevention of STDs were both frequently discussed during the interviews and focus-group discussions. Both trained and non-trained participants were relatively well-versed in issues related to transmission and prevention of STDs, although trained respondents were able to mention more possible modes of transmission than their non-trained counterparts. Knowledge of transmission routes was found to be lower among trained rural women than those trained in urban areas, hence so was their knowledge of prevention. In the comparison township, women's discussions of STD transmission were somewhat confused, and women did not have a clear understanding of how to prevent STDs.

Transmission of STDs through sexual intercourse with infected people and prostitutes was mentioned most often by respondents. Transfusion of infected blood and contaminated injection materials were also mentioned by a large number of respondents, whereas mother-to-child and homosexual transmission of STDs was rarely mentioned. A number of misperceptions regarding transmission of STDs still exist, even among trained respondents. Some respondents thought transmission could occur through sharing clothes, touching an infected person, or sitting in public places. Both trained and non-trained respondents consistently mentioned practising monogamy, being faithful, and avoiding sexual intercourse with prostitutes as ways to avoid contracting an STD. Fewer respondents mentioned the use of condoms, ensuring safe blood transfusion, and using disposable injection materials.

"Having sex with infected persons or prostitutes, transfusion of contaminated blood, wearing an infected person's clothes, and sitting on a contaminated seat are the major routes of STD transmission." (A trained urban woman from Dawei)

Participants' knowledge of STDs was often incomplete, however. A number of issues that had been covered in the life-skills training activities were not discussed by women during the evaluation. These include the need to consult with medical personnel for treatment of 
STDs, the importance of following prescribed treatment, the need for partner notification, and the link between the presence of STDs and the risk of infection with HIV/AIDS.

Women mentioned having received information regarding STDs from a number of sources. Many non-trained participants had heard about STDs from their trained friends and family members. Other sources included health talks by STD teams, pamphlets, journals, and magazines.

\section{Knowledge of and Attitudes Towards HIV/AIDS}

The life-skills training section on HIV/AIDS covered topics related to infection, transmission, prevention, attitudes towards people living with HIV/AIDS, and care and counselling of those living with HIV/AIDS.

Most respondents had heard of HIV/AIDS, although some non-trained women and many women from the comparison area did not know what HIV actually was, or the difference between HIV and AIDS. Most of the respondents could identify eh-ai-de-as (AIDS) as a disease that gradually affects the ko khan ah (immune system, literally "body's strength to defend"), and that an infected person can become sick with other serious diseases such as ah sote yawgar (tuberculosis, literally "lung disease") or wun thwar (diarrhoea, literally "having motion"). HIV/AIDS is of great concern in all townships, although in many townships women had never seen a person with AIDS. Overall, the study found that HIV/AIDS is perceived as a serious disease by all trained, non-trained, and comparison township participants.

Discussion of the modes of transmission was particularly animated during the focus-group discussions for both trained and non-trained women. Most frequently mentioned modes of transmission were sexual (both homosexual and heterosexual), blood, contaminated injection materials, and injection drug use. Transmission from a mother to her foetus and transmission through breastfeeding were less frequently discussed. There was some confusion regarding narcotic drug use among non-trained participants, with smoking of heroin sometimes mentioned as a mode of transmission. Trained respondents generally knew that injecting drugs and sharing needles were potential modes of transmission. Razor blades, tattoos, tooth extractions, sharing toothbrushes, and acupuncture were also mentioned as possible routes of transmission by a number of respondents. Some women mentioned that HIV could not be transmitted through daily activities such as kissing, touching, and sharing clothes. There was little difference in the knowledge of transmission between trained and non-trained women, or between rural and urban areas. Fewer modes of transmission were generally mentioned in the comparison township.

"HIV can be transmitted by having sex with prostitutes, sharing contaminated needles, sharing the same utensils, through ear-piercing instruments, public toilets, and through the air in public places." (A non-trained urban woman from Hinthada)

"Daily activities cannot transmit the virus. Kissing, handshaking, sharing food from the same plate, sharing clothes, and sharing the same mattress cannot transmit the disease because they do not involve blood and semen." (A trained urban woman from Mahaaungmyay) 
Prevention of HIV infection was also enthusiastically discussed during the interviews and focus-group discussions, with being faithful and practicing ta lin ta maya (monogamy) dominant topics of conversation. A few non-trained women said that they were not at risk because their husbands were faithful and did not engage in risky behaviour. Avoiding extramarital sex and using condoms when visiting prostitutes were also mentioned as important. A number of women mentioned safe blood transfusion, avoiding unnecessary injections, using disposable injection materials, and avoiding injection drug use as well. As with transmission, the differences in knowledge of prevention were minimal, although fewer means were known in the comparison township. Almost all women knew that AIDS is incurable, and that prevention of infection is the only available weapon against HIV/AIDS.

"I heard a lot about AIDS but do not know what HIV is. I don't think I can get AIDS because my husband is faithful to me. But it can be prevented by avoiding extreme sexual pleasures, being faithful, using disposable injection materials, and receiving clean blood." (A non-trained urban woman from Mahaaungmyay)

All trained and some non-trained women thought that people living with HIV/AIDS should be treated as normal people and would give them support to help overcome their pain and suffering. Almost all the respondents talked about boosting the morale of those infected with HIV, and most of the trained respondents were ready to give a helping hand to infected people as well as to their families. A few non-trained and comparison group women would, however, prefer to provide support from a distance. People from townships where HIV/AIDS is visible had a more pragmatic approach than those from townships where it is less obvious. Especially in Dawei, Lashio, and Myitkyina, trained respondents felt that people living with HIV should be treated the same as other people and cared for when they became sick.

"We could find some light jobs for HIV-positive people while they are still in good shape. So they can earn something before they really got sick." (A trained urban woman from Dawei)

Most respondents could identify the common signs and symptoms of AIDS-related illness. Pane lar dae (weight loss), chaung soe (cough), phyar (fever), wun thwar (diarrhoea), ah kyaik (enlarged glands, literally "lumps"), and ah yay pyar yawgar (skin disease) were mentioned throughout the study. A few trained women added ah sote yawgar (tuberculosis), met ka yu (oral thrush, literally "mouth plagues"), and yay yone (herpes) as opportunistic infections. All trained and most non-trained participants understood that people who are HIV-positive may look no different from uninfected people. Knowledge of the potential manifestations of HIV/AIDS was particularly low in the comparison township.

All trained participants and some non-trained participants had a substantial amount of knowledge about how to take care of a person living with AIDS. Some could even speak in detail about taking care of an infected person at different stages of the illness. In addition to medical care, financial, moral, and religious support was frequently mentioned throughout the evaluation. 
Trained participants said that people living with HIV/AIDS should not donate blood and should use disposable needles and condoms in order to avoid spreading the disease. Most trained participants said that infected people should keep healthy, seek regular medical care, try not to spread the disease to others, and try to prevent other opportunistic infections. Good personal hygiene, regular exercise, good ventilation, nutritious food, and meditation were common suggestions that would be given to an infected person.

\section{Sexual Decisionmaking}

One of the aims of the life-skills training was to improve women's ability to make decisions regarding sexual matters.

In general, respondents reported that they participated with their spouses in household decisionmaking (e.g., regarding household finances), regardless of training or residence. This was not the case for sexual decisionmaking, however; most women reported never having discussed sexual matters with their husbands. Some of the trained participants had talked to their spouses about birth spacing, and a few had engaged in limited discussions on sexual decisionmaking and the prevention of STDs. These women urged their spouses not to visit prostitutes and to be faithful. Only a few requested that their husbands use condoms if they had extramarital affairs. The reasons for not discussing sexual matters varied from simple shyness to the generally submissive and deferential behaviour of married Myanmar women. Most groups said that in Myanmar tradition, culture, customs, and religion are factors that prohibit women from talking openly about sex. In addition, most of the women interviewed said that they trusted their spouses unquestionably, and, therefore, they had no need to talk to them about sexual matters or prevention of infection.

"I discuss household decisionmaking with my husband, but not sexual matters. Being a Myanmar Buddhist woman, it is shameful as well as disgraceful to talk about sex." (A non-trained urban woman from Bago)

"I never talk to him about sex. It's too embarrassing. However, I tell him not to go to Karaoke bars. Men might visit prostitutes behind our backs. We can never know their tricks." (A trained rural woman from Mahaaungmyay)

"We don't discuss sex. I trust my husband completely. And I'm sure he doesn't have any extramarital affairs." (A non-trained urban woman from Pakokku)

\section{Sexual Practices and Condom Use}

The life-skills training programme also aimed to encourage safe and healthy sexual practices, including the use of condoms.

Most of the women in the survey mentioned that their husbands do not like to use condoms at home with their wives. For the purpose of birth spacing, women prefer to use injections or oral contraceptives. According to the women interviewed, spouses do not use condoms because they trust each other, and they think that condoms cannot guarantee full sexual pleasure. Some women also worried that a condom could be left inside them after intercourse, and others believed that they could not bear the friction of the rubber. All respondents expressed the belief that it is not always possible for a couple to use 
condoms, as they may want children or because condoms are an expensive choice of contraception.

"Condoms are expensive. It is about 15 Kyats per condom. It is much cheaper to use injectable contraceptives." (A rural married woman from Hmawbi, the comparison township)

Trained women felt that the opportunity to learn about the condom and its proper use was very useful. It also helped them to realise that, while AIDS is a dreadful disease, it is easily preventable. Despite this, very few expressed a willingness to use condoms with their husbands. Non-trained respondents, especially from the comparison township and in rural areas, believe that the use of condoms in marital relationships is evidence of adultery or wrongdoing. Condom use was also labelled as proof of contact with prostitutes. Most of the married women, regardless of training or residential status, felt that if their husbands used condoms with them, they would feel wun ne (sad), seik soe (furious), thit sa pauk (betrayed), and gon ma shi (dishonoured), thus harming the marriage. If their husbands began using condoms for no apparent reason, they would certainly feel that the husband must have had an extramarital affair or contracted an STD from a sex worker. Some respondents said that husbands would feel the same if the wife initiated condom use. On the other hand, some women thought that birth spacing could be an excuse for condom use, saying that other forms of contraceptives harmed their health. Some respondents from the comparison township and from non-trained groups had never seen condoms.

"Married men never use condoms with their wives. We trust each other and are always faithful." (A trained urban married woman from Dawei)

"If I suggested that my husband use a condom, I think he would kill me. He might think I am being unfaithful to him and caught up in trouble." (A non-trained urban woman from Mahaaungmyay)

The discussions highlighted the fact that while men do not use condoms with their spouses, some may use them outside marriage. The majority of the respondents believed that it is common for men to visit prostitutes. The number of men who reportedly do so varied between townships. There was a general consensus, however, that many men have extramarital affairs of either a commercial or non-commercial nature. Some respondents believed that alcohol, peer pressure, and a lack of knowledge of the possible health risks were factors contributing to a man's decision to visit prostitutes. In addition, a few respondents felt that the easy availability of condoms, contraceptives, and antibiotics for STD infections encourages men to have extramarital affairs.

"I told him for the sake of the family's health and welfare he must be faithful. Not every man, but philanderers, desirous and lustful men, might visit sex workers and have extramarital affairs." (A trained rural woman from Mahaaungmyay)

Trained urban women, in particular, mentioned that men might use a condom with prostitutes. Condom use with non-commercial sexual partners was an ambiguous issue. Most of the respondents did not think that men would use condoms with their mistresses 
or other non-commercial sexual partners; women cited thant sin (purity) and the fact that there was no need to worry about STDs as these sexual partners were not prostitutes. 
"I heard 60 percent of men use condoms with sex workers; however, they don't use it with their mistresses. If my husband wanted to use a condom, I would feel like I was being betrayed." (A non-trained urban woman from Lashio)

Most of the trained urban women responded that if they suspected their husband of having extramarital affairs, they would encourage him to use condoms, although it is unclear how much they could actually influence his behaviour. The strategies varied from one person to another. For example, some women would first ask their husbands to cease the affair, and, if he would not, to use condoms. Others said that they would urge their spouses to use condoms whenever they have an affair outside the marriage. Non-trained women and even trained rural women generally reported being unable or unwilling to have such conversations with their husbands.

Non-trained women and women in the comparison township had difficulty persuading their husbands to use condoms. Some respondents expected violent reactions from their spouses, who would think their wives were probing into their lives outside the marriage, while others were simply too shy to talk about using condoms. 


\section{LIFE-SKILLS TRAINING FOR YOUTH}

All trained youth interviewed for the evaluation had a relatively comprehensive understanding of life skills and HIV/AIDS. Some non-trained youth heard and knew about the training from their friends and colleagues in the community.

Trained youth could discuss in detail the training programme and its contents. They said that good decisionmaking, thoughtful assessment of needs and problems in life, and friend-to-friend education were the most interesting life-skills concepts. In particular, young people felt that the friend-to-friend education component had helped them informally pass along information to their friends regarding issues discussed in the training. The respondents said they had learned a considerable amount about HIV/AIDS, reproductive health, birth spacing, and the care and counselling of people living with HIV/AIDS. The training also became an entry point for young people who were interested in health, social, and volunteer activities. Tangible results were demonstrated in reported increases in Red Cross youth membership after the training courses finished.

The training also had a significant impact upon the personal lives of participants. Many reported they had become more careful, thoughtful, and considerate. They said that, formerly, they were easily persuaded by their friends to perform an de yar shi aри ати (risky acts), but that now they had stopped those risky acts and had begun to tell their friends about the dangers of HIV/AIDS and STDs. They received not only theoretical knowledge but also practical knowledge on how to protect themselves and how to help others. Some participants responded that friends and community members talked highly of them, as their knowledge of HIV/AIDS and life skills was helpful in the community.

\section{Life Skills}

The general life-skills component of the youth training programme was similar to the lifeskills training of married women in that it included discussion of the important characteristics of a good friend, good decisionmaking practices, and the importance of friend-to-friend education and support. In addition, training included some discussion of the physical and emotional changes that young people experience.

Regarding life-skills issues, there were few differences between trained and non-trained, and urban and rural youth, although trained youth and non-trained youth from urban areas tended to have a better developed understanding of many of the issues. Those from the comparison township were particularly lacking in the skills and knowledge required to enable them to address important needs and problems in their lives.

Most trained youth described a good friend as someone with whom they could share information and who provides emotional support in times of trouble. Young girls added that the ability to keep information confidential was also an important aspect of being a good friend. The majority of young men said they usually talk to their friends if they have problems, although if the problems are pressing they prefer to talk to their parents. A few male respondents said they sometimes talk to teachers when they have problems. In contrast, the majority of female respondents talk to their siblings, rather than to their friends. Most of the girls interviewed mentioned that when they need to talk to someone they go to their elder sisters, female relatives, and married women in the community. 
"If I have minor problems I talk to my friends. But if it is a major one, I need to tell my parents. It is easier for me to discuss with friends, but sometimes only parents can help." (A trained rural male youth from Dawei)

Most trained youth answered that they would like to tell their parents about their boyfriends or girlfriends. Most of the non-trained young women also wanted to let their parents know about any affairs, giving the reason that parents are thoughtful, experienced, and can judge right from wrong. If the parents knew, they could give advice on social matters and also could discourage or even prevent premarital sex. Those who did not want to tell their parents said that parents could interfere with their affair, scold them, and stipulate stricter rules. These young people also said that they did not want to lose their boy/girlfriend if he/she did not meet with the parents' approval.

"I will tell my parents about my boyfriend later on but not immediately. I think parents are more thoughtful and decisive. They can judge the character and honesty of my boyfriend." (A trained urban female youth from Myitkyina)

"Usually young people do not tell their parents about their girl- or boyfriends. If they disagree, there can be a lot of problems." (A trained urban male youth from Lashio)

All trained participants were well informed regarding the changes that take place during adolescence. They categorised the physical changes in boys as increased weight and height, hair growth, and vocal hoarseness, and in girls as breast and hip development and onset of menstruation. Both groups said that emotional changes include excitability, desire for independence, and worry about their bodies and looks.

\section{Knowledge of Sexually Transmitted Diseases}

MRCS's life-skills training curriculum covered a number of issues related to STDs, including transmission, seriousness, treatment, symptoms, and the relationship of STDs to the transmission of HIV.

All respondents replied that they had heard about STDs. Some, however, especially nontrained youth and those from the comparison township, had limited knowledge of STDs. Male respondents were more aware of the details of STDs than their female counterparts. Among female respondents, students knew more about STDs than those who were working. Most trained youth, from both urban and rural areas, spoke of STDs in their own dialect or slang, and used such terms as pha kyo (broken by a prostitute), lu pyo nar yawgar (young boys' disease), and karlathar yawgar (venereal disease).

"I hear about it quite often but do not know very much. It happens among those seeking extreme sexual pleasures." (An urban female youth from Patheingyi, the comparison township)

Most trained youth knew that STDs are transmitted by sexual contact. Sipalit (syphilis) and yay yone (herpes) were the most well-known STDs, followed by gono (gonorrhoea). A few respondents mentioned bin (swollen lymph glands) and ngar myet si (molluscum contagiosum, literally "fish eye"). Nyaung kya (discharge), see kyin (tingling urination), 
see pu (difficulties in urination, literally "hot urine"), and lain tan ah nar phyit (genital ulcers, literally "sex rod has an ulcer") were also noted during discussions. There was, however, a lot of confusion between ko yay pyar yawgar (leprosy) and other skin infections and STDs, even among trained youth. STDs were said to be common among young people, and some participants thought lain tan ah nar phyit (genital ulcers) and gono (gonorrhoea) were the most common STDs.

Hens (prostitutes) and line (women with multiple sexual partners) were blamed as the source of STD infections. Most of the respondents answered that STDs are transmitted through sexual contact, blood transfusions, and contaminated injection materials. A few replied that STDs could be transmitted from a pregnant mother to her foetus, from gaping wounds, and through skin-piercing tools. The majority of respondents knew that sexual intercourse without a condom is the main route of STD transmission.

Trained youth agreed unanimously that the best preventive measure for STDs was to avoid unprotected sexual intercourse. Avoiding sexual intercourse with prostitutes and using condoms were widely discussed as other preventive measures. Some young people also mentioned avoiding unnecessary injections or unnecessary blood transfusions. Some non-trained youth and most young people in the comparison township thought that good personal hygiene, not wearing another person's clothes, and avoiding seats in public places all would prevent transmission. The phrase ma kyo aung ka kewi (STD prophylactics, literally "protect so as to avoid breaking") was used by many, including a few trained respondents, as an effective prevention, implying the use of penicillin or traditional methods before sexual intercourse. Some trained youth suggested that young people should be tested for STDs at least two to three times a year for early detection of infection.

"It is better to avoid having sex with prostitutes. If not, use condoms. One way to prevent STDs is to take prophylactic injections before or after sex. One should take two or three injections to make sure that it is not contracted. Otherwise, one can catch it when the effect of the injections wears off." (A non-trained urban male youth from Pakokku)

As with the married women, the importance of treating STDs completely and the connection between STDs and HIV/AIDS were not discussed during the interviews and focus-group discussions with young people. Only a few respondents mentioned the importance of consulting with medical personnel and taking the full course of a prescribed antibiotic treatment.

Many of the trained respondents said that they had learned about STDs during the training and that they had been confused before the training. Some of the non-trained youth and those from the comparison township had become aware of STDs through friends, elders, books, and health education. The quality of their knowledge, however, was not always consistent. 


\section{Knowledge and Attitudes Towards HIV/AIDS}

MRCS's life-skills training activities included a major focus on knowledge and attitudes towards HIV/AIDS. Transmission routes, prevention techniques, and attitudes towards and care of and counselling of people living with HIV/AIDS were all included in the training.

All youth respondents mentioned that HIV/AIDS was the most dreadful and dangerous disease of their time. Some of the trained youth said that before training they thought that HIV/AIDS was not common in their community, but after attending the training they realised that it could become a serious disease in their community.

All respondents in this study had heard about HIV/AIDS, and most of them, regardless of training or residential status, knew specific details. A few non-trained youth and those from the comparison township were confused about the difference between HIV and AIDS. In general, knowledge of HIV infection, transmission, and prevention was very high among the trained participants, and satisfactory among most of the friends of trained youth. A few young people from the non-trained population and some from the comparison township lacked certain important information, but generally they had basic knowledge of HIV/AIDS issues. On the whole, more young people were aware of HIV/AIDS than of STDs.

Many answered that women contract HIV primarily from their husbands. Fishermen, truck drivers, and those working in Ranong (Thailand) were believed to transmit the virus to their wives. Meinma pyat (sex workers, literally "spoiled women") could get the disease from their clients, and victims of rape could also contract the virus from their assailants. Other modes of transmission to women mentioned were blood transfusions, injection materials, and sharing needles while using narcotics; respondents also knew that a pregnant mother could transmit the virus to her baby. While all of these were mentioned by most respondents, the trained groups' answers were more detailed. It was believed that men get the virus through homosexual and heterosexual intercourse with infected people and through blood, needles, skin-piercing materials, and by injecting drugs. Having multiple sexual partners, living ah pyaw lite (hedonistically, literally "follow the fun"), and injecting drugs were mentioned as risky behaviours. Truck drivers, fishermen, drug addicts, and prostitutes were mentioned as high-risk groups.

A few non-trained youth and some in the comparison township thought that sharing the same utensils and toilets was a possible mode of HIV transmission. Some thought that simply touching someone with HIV could cause infection, while others thought that sharing the same cigarette could cause infection (because of saliva) or that mosquitoes could transmit the virus. A few mentioned sharing clothes as a possible route of HIV transmission. Most assumed, however, that daily activities were not dangerous.

"It can be transmitted by having sex with infected people, infected blood, contaminated syringes, and needles. Moreover, sharing the same food, staying close to an infected person, and sharing utensils can transmit the infection." (A non-trained rural male youth from Paan) 
Overall, attitudes towards people living with HIV/AIDS were very positive, especially among trained youth and their friends. In the comparison township, attitudes were found to be more negative. Most of the trained youth and some of the non-trained youth said that an HIV-positive person looks exactly like an uninfected person. On the other hand, many of the young people interviewed said that they could identify a person who was ill with AIDS, having acquired their information through the mass media.

"HIV-positive people look like normal people. They can live, work, and travel normally. If they develop AIDS, pane lar dae [weight loss], phyar [fever], wun thwar [diarrhoea], ah yay pyar yawgar [skin diseases], and met ka yu [oral thrush] will appear one by one." (A trained rural female youth from Dawei)

A few non-trained youth from rural areas and some from the comparison township felt uneasy about being too close to an infected person. Some said they would like to help from afar. A few respondents from the comparison township said it is a kyat tha yay ma shi (disgraceful) and gon am shi (dishonourable) disease in Myanmar, and they would therefore rather cover up the illness and the cause of death to honour the person and his/her family. Most young people from project townships reported being willing to visit an infected person, in contrast to those in the comparison township who would be reluctant to make such a visit.

"I don't think we should visit an infected person. I'm scared of catching it." (A non-trained rural female youth from Lashio)

"If a friend of mine is HIV-positive, I don't want to visit him. I could support him with money or things but from a safe distance." (A rural male youth from Patheingyi, the comparison township)

Most of the trained respondents could discuss in detail how to care for an infected person. If a person is still capable of living a normal life, help should be supportive, such as accompanying the person to health centres, visiting the person regularly, and providing disease updates. If an infected person becomes ill, home-based care would be necessary. Most trained youth said that, apart from medical treatment, they could provide psychological, social, and financial support to a person with HIV/AIDS. Keeping their hopes alive and seit dat tet (raising morale) through simple encouragement, ta yar htai (meditation), and ta yar haw (preaching) could provide psychological support. Moreover, frequent visits by friends and relatives would provide social support. Many non-trained urban youth could also discuss these issues, but those in rural areas and in the comparison township were much less clear on issues related to care of people living with HIV/AIDS.

"We will keep the person happy, help with the household chores, recite religious teachings, and provide nutritious food." (A non-trained urban male youth from Pakokku)

\section{Sexual Practices and Condom Use}

As with the MMCWA life-skills training activities, one of the major aims of the MRCS life-skills training programme was to give young people the knowledge and skills necessary to encourage safe sexual practices, including the use of condoms. 
All trained youth knew what a condom was and that it could prevent STDs and pregnancy. Most of the respondents had seen a condom, although for many this had only been during the training itself. Many non-trained female youth had never seen a condom out of its package. Knowledge of the condom and its use was lower in the comparison township than in the project townships. The majority of respondents were reticent about discussing condom use. Some trained urban male youth could recount anecdotes about condom users/non-users but personal experience of condom use was not disclosed, even in male-only discussion groups.

A sizeable proportion of all groups said that ain taung makya mi lain set san (sexual intercourse before marriage) is common among boys. Most said that premarital sexual intercourse would be with prostitutes, although many also said that it might be with girlfriends. Those who had had intercourse with their girlfriends said that most of the sexual encounters were unplanned. Put that (caressing), kai (touching), and nan (kissing) produced uncontrollable desires and led to sexual intimacy. However, some boys had had intercourse in order to prove their masculinity and were proud to have a reputation as a lain kait sa lite sar (philanderer, literally "follower and eater related to sexual intercourse").

"Some boys love boasting about their sexual experiences and showing their masculinity. They brag about how they have sex with sex workers." (A trained urban male youth from Myitkyina)

Premarital sex among women is not uncommon, but it is not considered thint lyaw (proper) and is not generally accepted in society. Although most of the young women did not approve of premarital sex, some had consented to it. The reasons girls gave up their virginity varied from chit thet thay (proof of love) and lone wa yone (total faith) in their boyfriends to weak negotiating skills and inability to control ta nar (lust). Most female respondents discussed how premarital sex could lead to embarrassment, being the target of gossip, unwanted pregnancy, STDs, and HIV infection. They said that boys were never serious and that it was girls who had to suffer all the consequences of having premarital sex.

"Some girls may have premarital sex depending upon the situation. Some boys are ta zut toe lote [pushy and domineering]. It can happen while meeting in a secret hideout." (A trained rural female youth from Myitkyina)

"Myanmar girls do not accept premarital sex. Shyness and religious and cultural restrictions to maintain ah pyo sit [chastity] and the consequences of premarital sex strongly inhibit Myanmar girls from shote [flirting]." (A trained rural female youth from Myitkyina)

Most of the boys included in the evaluation, regardless of training or residence, said that it is common for boys to talk about sex among themselves fairly freely and openly. Some said that they learned about sex from ah pyar kar (pornographic movies), which were frequently shown at video parlours. In contrast, only trained urban and rural girls and friends who received information from them in urban areas openly discussed sexually related behaviours and practices. Non-trained girls in rural villages and young people from the comparison township did not discuss the subject. Most girls did not feel 
comfortable talking about sex. The reasons given were shyness; religious, social, and cultural restraints; and the submissive nature of women in Myanmar. Some female respondents had, however, discussed sex with their older friends or with married women out of curiosity or in order to gain knowledge. A few girls also mentioned talking about sex with their boyfriends. Mostly they mentioned it in vague terms, in contrast to the detailed discussion among boys. Most respondents said that their parents and elders did not approve of young people talking about sex. They were worried that the young person would get into trouble, with promiscuity as a consequence, and they also might think it against their religion, culture, and tradition. Some respondents reported that it is rude to talk about sex within a Myanmar family setting. 


\section{CONCLUSIONS AND RECOMMENDATIONS}

The findings indicate that the life-skills training programme has had a beneficial effect in terms of improving the knowledge base of the women and youth directly exposed to the training. It also appears to have had a positive effect on their reported attitudes towards people living with HIV/AIDS. In both these content areas consistently more accurate or less stigmatising responses were given by trained participants than by non-trained participants or those from the comparison townships.

Overall, knowledge of HIV/AIDS was greater than that of STDs more generally, with fewer differences in HIV/AIDS knowledge between trained, non-trained, and comparison township participants. This is not surprising, given the focus on HIV that characterises mass media and other health education efforts in Myanmar, as well as in most other countries. The differential (and better) knowledge of STDs among trained participants and, to a lesser extent, among those in project townships where the life-skills training had taken place corroborates the positive impact the training program has had in delivering needed information. Because accurate information regarding STDs is harder to come by in Myanmar, the more accurate knowledge of these diseases among trained youth and women is likely to be due to the life-skills training.

Knowledge of HIV, STDs, and other reproductive health topics was also consistently better among urban than rural participants, regardless of whether the participant had received life-skills training. There was also a suggestion that non-trained individuals in project townships had better knowledge than individuals in the comparison townships where no life-skills training had taken place. One must exercise caution in drawing this conclusion, however, given the courtesy bias inherent in such a participatory approach and the limited number of comparison townships.

A number of conclusions and practical recommendations are suggested by these findings.

\section{Improving Knowledge}

On almost all topics, knowledge was found to be greater among trained women and youth than among their non-trained friends and family and those from the comparison townships. In many instances knowledge among the non-trained friends of a trained participant was greater than that of individuals from the comparison townships; however, it was rarely equal to that of the young people and women who had been trained directly, suggesting that the anticipated multiplier effect of the friend-to-friend or community counselling may not have been effective. To be more effective as an intervention, it is essential that this component of the programme receive greater attention.

To increase the effectiveness of knowledge dissemination, future life-skills training activities need to have a stronger component to support the individuals' capacities to act as friend-to-friend or community counsellors. This will require ongoing support to the counsellors, including access to accurate information and an adequate referral system. 
During the evaluation it was noted that women and youth who had undergone training still had a number of misperceptions regarding specific aspects of birth spacing, STDs, and HIV/AIDS. There were also a number of areas in which knowledge was incomplete.

Training manuals and materials should be revised to include specific references to the misperceptions and gaps in knowledge identified in the course of this evaluation. Future training should provide more detailed information on:

- different methods of contraception;

- the link between the presence of STDs and the risk of HIV transmission;

- the importance of partner notification among individuals with STDs;

- the importance of adhering to prescribed courses of antibiotic treatment;

- the importance of discouraging prophylactic use of antibiotics, especially among youth;

- modes of transmission of and prevention of STDs/HIV; and

- ways of addressing the confusion between STDs and skin diseases.

Core trainers who undertook the participatory evaluation should be supported in undertaking a comprehensive review and revision of the life-skills training curriculum and training materials.

In the eight project townships included in this evaluation, the life-skills training intervention had been introduced essentially as a one-time intervention to train urban and rural youth and married women of reproductive age. While no evaluation of the training's impact was conducted immediately after the training sessions, one can infer from the pattern of knowledge found in this evaluation (i.e., good general knowledge, but often incomplete information regarding specific details) that either the information from the life-skills curriculum was not fully absorbed in the training sessions or was forgotten over time. Regular refresher training of life-skills trainees would help to reinforce their knowledge and skills and serve to fill in any deficits in knowledge.

Regular refresher training should be provided to participants who have successfully completed the life-skills training programme. Those participants who have made attempts to use their skills in friend-to-friend or community counselling should be given priority for such refresher training.

\section{Improving the Impact of Life-skills Training on Behaviour}

Reports of condom use by both women and youth were very low, and the life-skills training activities did not seem to have had an impact in this regard. Condom use among youth was generally low because of the method's association with promiscuity and commercial sex. Similarly, condom use among married couples was low and was stigmatised because of a perceived connection with sex workers, unfaithfulness, and STDs.

Changing such pervasive community perceptions is a long-term challenge, and the extent to which training programmes alone can influence the use of condoms for preventing STDs is uncertain; however, training programmes may help demystify condoms by allowing participants the opportunity to see, touch, and play with them. Many women and, to a lesser extent, young men had never seen a condom, especially one out of its wrapper. 
Life-skills trainers should increase the amount of time spent in training sessions encouraging participants to open, touch, and unroll condoms. A range of condom brands should be made available for participants to examine.

In the evaluation discussions, women generally did not express any perceived personal risk of STDs or HIV. Most believed that it was common for men in their communities to visit sex workers, that condom use among these men was generally low, and that this posed a risk for both STDs and HIV. On the other hand, almost all women said that they did not need to worry because their husbands were faithful. While it may be that some women personally acknowledged their risk of infection but were understandably reluctant to admit this to the interviewers, it can be concluded that greater efforts should be made to help women better understand their personal risks.

In the course of the life-skills training for both women and youth, exercises should be included to promote a more personal assessment of risks related to the transmission of STDs, including HIV. This could be done through the use of case histories, role-playing, and the review of specific behavioural scenarios that might be encountered in the course of friend-to-friend counselling.

Sexual decisionmaking was found to be dominated by the husband, even for women who had attended the life-skills training programme. While many of the trained women were able to discuss the importance of participating in sexual decisionmaking, most were still unable to do so. If future life-skills training activities for married women are to improve women's abilities to discuss and negotiate sexual decisions, it will be necessary for the curriculum to be revised to more rigorously address gender issues and gender roles.

Issues related to gender and the gender relations between women and their husbands must be included in future training activities for women if the training is to improve women's abilities to negotiate and discuss sexual issues with their husbands.

Many of the behaviour changes advocated by the life-skills training programme for women require complicity by the woman's husband. In light of this evaluation, it appears that there are a number of limitations to the assumption that giving women the necessary information and negotiating skills will enable her to change the sexual behaviour of her husband. If sexual behaviour change is to be a focus of future life-skills activities, mechanisms for including husbands in the programme need to be explored.

It is important to consider possible mechanisms for including men (specifically husbands of the trained women) in the life-skills training programme. Consideration should be given to the appropriateness of conducting training for wives and husbands either together or separately.

\section{Expanding Life-skills Activities}

The results of the participatory evaluation suggest that the women and young people who took part in the life-skills training programme clearly benefitted from such training in terms of their personal knowledge and their attitudes towards people living with HIV/AIDS. The latter is especially important in the environment of an emerging epidemic 
where stigma and discrimination against such people is common. Consequently, expanding access to this intervention in other townships of Myanmar should be pursued. Obviously, such expansion of life-skills training needs to be complemented by more targeted efforts to reach high-risk populations of men and women at risk of STDs/HIV, especially prostitutes and their clients.

Consideration should be given to expanding the life-skills training programme to additional townships in all states and divisions of Myanmar.

Within established project townships, local MRCS and MMCWA staff should consider expanding life-skills training and refresher training in order to provide a broader coverage of the intended target populations. They should also work with local health authorities to explore ways of reaching more high-risk populations with important knowledge and life skills.

\section{Strengthening the Process of Life-skills Training}

This evaluation of life-skills training has highlighted a number of ways in which future activities could be strengthened. As activities expand to more townships, it will be important to make evaluation and monitoring a more integral component of the life-skills training programme. This will help to ensure that central-level planners are able to respond swiftly to any problems identified by the local implementing agencies.

A prospective system to monitor and assess the training activities should be established as an integral part of the life-skills training programme. Such a monitoring system should include pre-and post-testing of trained participants' knowledge, observation checklists for training, periodic focus-group discussions with participants, and in-depth interviews with trainers.

Many of the limitations of the current life-skills training activities that were identified through this evaluation are common to both the MMCWA and the MRCS training programmes. There has been, however, very little coordination and discussion between these groups, particularly at the township level. Sharing of information between township trainers would encourage discussion of the strengths, weaknesses, opportunities, and constraints of the life-skills training, and would facilitate future planning and strategy formulation.

Experience-sharing workshops for township-level trainers should be conducted. These could be a component of the refresher training exercises recommended above. Such workshops should involve trainers from both MMCWA and MRCS to ensure effective exchange of experience and ideas.

The National AIDS Programme of Myanmar has recently launched a pilot behavioural study as part of its HIV/STD sentinel surveillance system. The young people attending the life-skills training sessions could be an appropriate and important source of behavioural data for such surveillance. A one-page behavioural questionnaire could be completed by young people who attend the life-skills training. Sequential studies could assess behavioural change over time and could be used as one, albeit incomplete, indicator to measure the impact of the programme. 
With the involvement of the National AIDS Programme, consideration should be given to incorporating a one-page behavioural questionnaire into every youth training session to obtain baseline behavioural data on sexual and other risk behaviours of youth.

\section{Ensuring the Appropriate Choice of Participants}

The focus of the training of married women was on women between 20 and 40 years old. It is known, however, that the majority of women involved in the training activities were over 30 years of age, and this is reflected in the mean age of married women in the current evaluation, which was 33 years. It is important to ensure that younger married women are included in the life-skills training activities, as they are often unaware of reproductive health issues.

Future life-skills training activities of MMCWA should make every effort to include a broad range of married women, particularly young married women who often do not have access to other sources of information on birth spacing and other relevant topics.

Another issue regarding the selection of participants for life-skills training at the local level is the likelihood that those who are trained will become actively engaged in friendto-friend counselling. The multiplier effect of this intervention ultimately depends on such post-training activity. It was not clear from this assessment what criteria were used in the selection of participants for the initial training efforts. It appeared, however, that only some of the initial participants made a significant effort to inform neighbours and friends. Greater efforts should be made to seek out participants who will be effective proponents of community mobilisation. This may require recruiting participants from beyond the registered membership of MRCS and MMCWA.

MMCWA and MRCS should review their selection criteria for choosing participants for the life-skills training programme and should consider recruiting a broader range of participants, emphasising those most likely to engage in community counselling activities. 